\title{
NUMERICAL SIMULATION OF PAVEMENT RESPONSE TO DYNAMIC LOAD
}

\author{
Nina Rapanová , Ján Kortišs \\ University of Žilina, Faculty of Civil Engineering \\ Univerzitná 8215/1, 01026 Žilina, Slovakia \\ ${ }^{1}$ Department of Highway Engineering \\ Ph:+42141/5135930. E-mail: nina.rapanova@fstav.uniza.sk \\ ${ }^{2}$ Department of Structural Mechanics \\ Ph:+42141/5135616. E-mail: jan.kortis@fstav.uniza.sk
}

\begin{abstract}
Road structures are loaded by heavy vehicles and also they have an influence of temperature changes, which cause a difficult stress and strain distribution over layers of the pavement and the subgrade. Knowing this, distribution of stress and strain can help to better understand the behaviour of the pavement during the service time. For this purpose, the mechanical characteristics like elastic modulus, Poisson ratio, or damping ratio have to be known. The special device is used for determination of these mechanical characteristics, which loads the surface of the pavement by a force impulse. The deflections are measured in the surroundings of point of load impulse. The signal can be evaluated by use of 2D or 3D calculation model of pavement construction. In this case was used the axially-symmetric 2D model. This reduced the time consumption of individual tasks solution. The article considers also the influence of boundary conditions on deflections of models with varying width. The following text describes findings acquired from numerical simulation of pavement response to dynamic load.
\end{abstract}

Keywords: calculation model, dynamic method, deflection

\section{Introduction}

The transport load as well as the weather conditions causes degradation of material of construction layers of pavement. Therefore it is necessary to have diagnostic procedures for obtaining information on current condition of the pavement. Using this information it is possible to determine residual service life or to suggest effective maintenance to eliminate the defects. Methods for determination of deformation characteristics can be divided into static and dynamic diagnostic methods. Presently, static methods of the pavement load are already worked out in detail. This article deals with methods of the dynamic load.

This article provides numerical simulation of load impulse of pavement, which in a simplified form takes into account the effect of deformation characteristics of pavement layers on the resulting deflection time curves [1], [2]. The shape of load impulse corresponding to the shape of load impulse of device FWD Dynatest is used for determination of the excitation force time curve [3]. This device is used commercially for measurement of the mechanical characteristics of the pavements. It is highly accurate, reliable and has a simple user interface.

\section{Description of Calculation Model}

The calculation model was created in the software Adina [4], using finite element method (FEM) [5], [6]. The calculation model represents the composition of the structural layers of the pavement on subgrade. Characteristics of the construction layers of pavement and individual thickness are shown in the Table 1. Parameters are changing depending on the pavement type in consideration of changes of asphalt layers modules caused by change of their temperature. Zero displacement at the edges of calculation model has been considered (Fig. 1). 


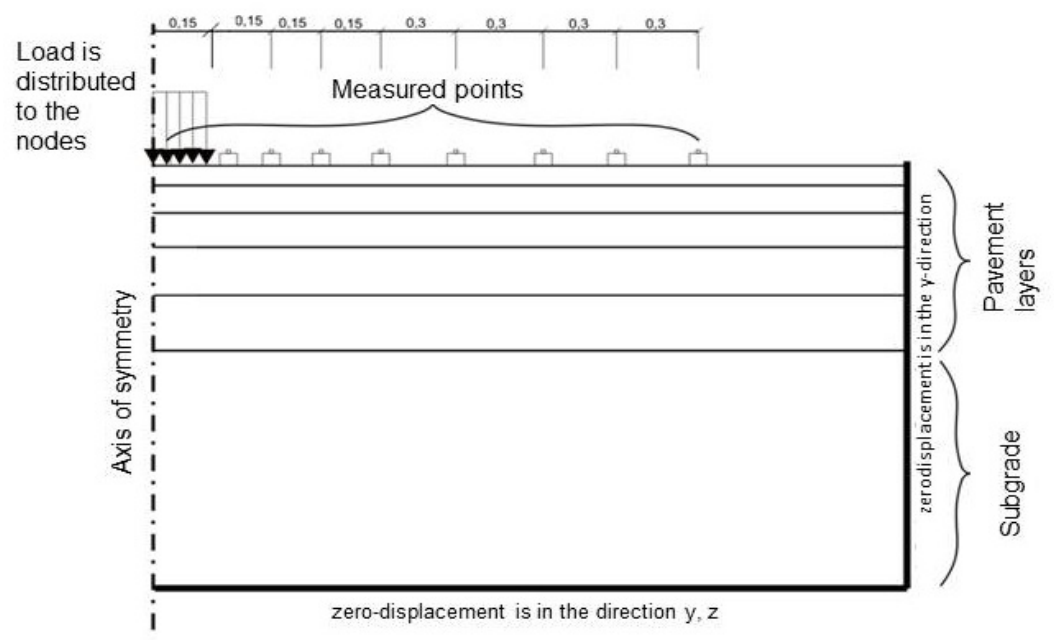

Figure 1. Scheme of road's 2D solid model with nodes where z-displacements were evaluated

Table 1. Material characteristics and thickness of modelled types of road pavements [7], [8]

\begin{tabular}{|c|c|c|c|c|c|c|c|c|c|c|}
\hline \multicolumn{2}{|c|}{ Semi-rigid pavement } & \multirow[b]{2}{*}{ Sign } & \multirow{2}{*}{$\begin{array}{c}0^{\circ} \mathrm{C} \\
\mathrm{E}[\mathrm{MPa}] \\
\end{array}$} & \multirow{2}{*}{$\begin{array}{l}11^{\circ} \mathrm{C} \\
\mathrm{E}[\mathrm{MPa}] \\
\end{array}$} & \multirow{2}{*}{$\begin{array}{l}27^{\circ} \mathrm{C} \\
E[\mathrm{MPa}] \\
\end{array}$} & \multirow[b]{2}{*}{ ? [kg.m-3] } & \multirow{2}{*}{$\begin{array}{r}0^{\circ} \mathrm{C} \\
\mu\end{array}$} & \multirow{2}{*}{$\begin{array}{r}11^{\circ} \mathrm{C} \\
\mu\end{array}$} & \multirow{2}{*}{$\begin{array}{r}27^{\circ} \mathrm{C} \\
\mu \\
\end{array}$} & \multirow{2}{*}{\begin{tabular}{|l} 
Nc max $=30.10^{6}$ \\
Thickness of \\
course [mm]
\end{tabular}} \\
\hline A1 & Material of layers & & & & & & & & & \\
\hline & Stone Mastic Asphalt & SMA11 & 7500 & 6000 & 3750 & \multirow{3}{*}{2370} & 0.21 & 0.3 & 0.4 & 40 \\
\hline & Asphalt Concrete (base course) & AC16L & 5700 & 4200 & 2000 & & 0.21 & 0.3 & 0.4 & 50 \\
\hline & Asphalt Concrete (road base) & AC16P & 4500 & 3050 & 1250 & & 0.21 & 0.33 & 0.44 & 70 \\
\hline & Cement bound granular mixtures & $\mathrm{CBGMC}_{8 / 10}$ & 2000 & 2000 & 2000 & \multirow{2}{*}{2100} & 0.22 & 0.22 & 0.22 & 160 \\
\hline & Crushed gravel & & 350 & 350 & 350 & & 0.3 & 0.3 & 0.3 & 200 \\
\hline & Subgrade & & 120 & 120 & 120 & 1800 & 0.35 & 0.35 & 0.35 & 250 \\
\hline & & & $0^{\circ} \mathrm{C}$ & $11^{\circ} \mathrm{C}$ & $27^{\circ} \mathrm{C}$ & & $0^{\circ} \mathrm{C}$ & $11^{\circ} \mathrm{C}$ & $27^{\circ} \mathrm{C}$ & \\
\hline A2 & Material of layers & Sign & $\mathrm{E}[\mathrm{MPa}]$ & $\mathrm{E}[\mathrm{MPa}]$ & $\mathrm{E}[\mathrm{MPa}]$ & ? [kg.m-3] & $\mu$ & $\mu$ & $\mu$ & $\begin{array}{l}\text { Thickness of } \\
\text { course }[\mathrm{mm}]\end{array}$ \\
\hline & Stone Mastic Asphalt & SMA11 & 7500 & 6000 & 3750 & \multirow{3}{*}{2370} & 0.21 & 0.3 & 0.4 & 40 \\
\hline & Asphalt Concrete (base course) & $\mathrm{AC16L}$ & 5700 & 4200 & 2000 & & 0.21 & 0.3 & 0.4 & 60 \\
\hline & Asphalt Concrete (road base) & AC16P & 4500 & 3050 & 1250 & & 0.21 & 0.33 & 0.44 & 90 \\
\hline & Cement bound granular mixtures & $\mathrm{CBGMC}_{5 / 6}$ & 1200 & 1200 & 1200 & \multirow{2}{*}{2100} & 0.25 & 0.25 & 0.25 & 190 \\
\hline & Crushed gravel & & 350 & 350 & 350 & & 0.3 & 0.3 & 0.3 & 230 \\
\hline & Subgrade & & 120 & 120 & 120 & 1800 & 0.35 & 0.35 & 0.35 & 250 \\
\hline \multicolumn{2}{|c|}{ Flexible pavement } & & $0^{\circ} \mathrm{C}$ & $11^{\circ} \mathrm{C}$ & $27^{\circ} \mathrm{C}$ & & $0^{\circ} \mathrm{C}$ & $11^{\circ} \mathrm{C}$ & $27^{\circ} \mathrm{C}$ & \\
\hline A3 & Material of layers & Sign & $\mathrm{E}[\mathrm{MPa}]$ & $\mathrm{E}[\mathrm{MPa}]$ & $\mathrm{E}[\mathrm{MPa}]$ & ? [kg.m-3] & $\mu$ & $\mu$ & $\mu$ & $\begin{array}{l}\text { Thickness of } \\
\text { course [mm] }\end{array}$ \\
\hline & Stone Mastic Asphalt & SMA11 & 7500 & 6000 & 3750 & \multirow{3}{*}{2370} & 0.21 & 0.3 & 0.4 & 40 \\
\hline & Asphalt Concrete (base course) & $\mathrm{AC16L}$ & 5700 & 4200 & 2000 & & 0.21 & 0.3 & 0.4 & 80 \\
\hline & Asphalt Concrete (road base) & $\mathrm{AC16P}$ & 4500 & 3050 & 1250 & & 0.21 & 0.33 & 0.44 & 100 \\
\hline & Ruggedized aggregates & MSK & 600 & 600 & 600 & \multirow{2}{*}{2100} & 0.25 & 0.25 & 0.25 & 250 \\
\hline & Crushed gravel & & 350 & 350 & 350 & & 0.3 & 0.3 & 0.3 & 250 \\
\hline & Subgrade & & 120 & 120 & 120 & 1800 & 0.35 & 0.35 & 0.35 & 250 \\
\hline
\end{tabular}

The solution time depends on the amount of elements connected with the amounts of equations. Firstly, the area, which represents the pavement layers, and subgrade was discretized by using 3D solid elements. It led to the big amount of elements as well as the demanding requirement for the computer capacity. After first attempts to solve this we realized that it would not be effective. The decision to decrease the amount of elements by using axial symmetry was made. So the geometry for model in z-plane was modified and the area was discretized by using axis symmetric 2D Solid elements. Comparing the results obtained in dynamic analysis it is obvious that there is no need to create complicated and time-consuming 3D model. A lot easier axially-symmetric model, which gives the same results, is sufficient. This is also evident from the following comparison of the time curve of road surface deflections in analysed points (Fig. 2). 


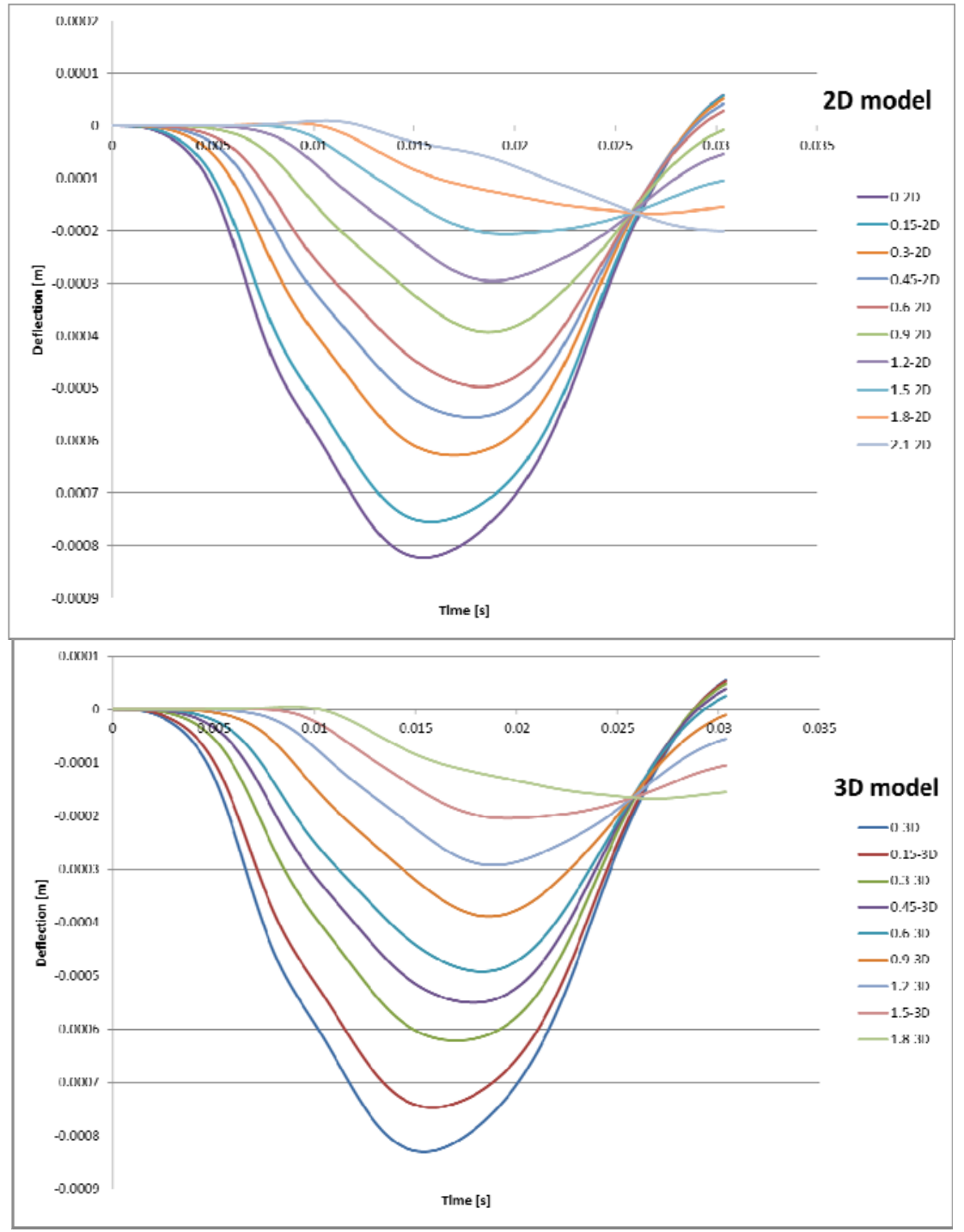

Figure 2. Display 2D and 3D model

For this reason only easier axially-symmetric 2D model of pavement construction was used for further analysis. This reduced the time consumption of individual tasks solution as far as the number of the equation system solutions significantly decreased.

The load is characterized by a pressure applied on the load plate differing in dependence on the load impulse (Fig. 3). Position of the points (nodes) in which the results were analysed (their distance from the axis of the load) was equal to the location of points for road surface deflection measurement (Fig. 2).

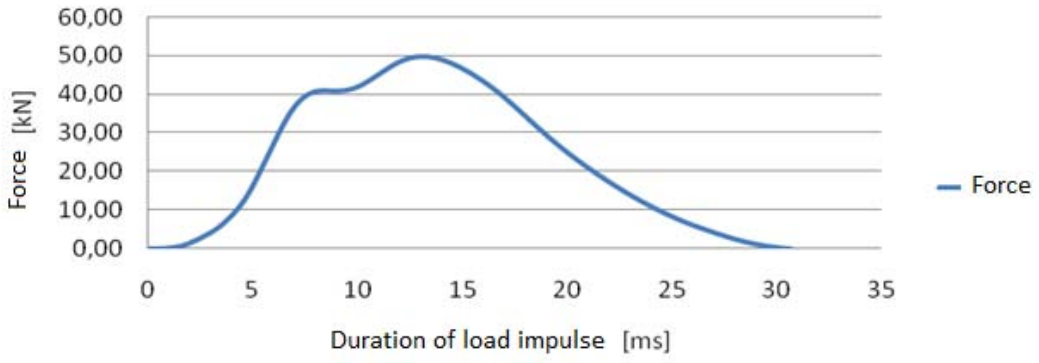

Figure 3. Time history of load impulse 


\section{Influence of Boundary Conditions of Calculation Model}

The dynamic analysis of influence of 2D model width changes on the resulting deflections was performed. Calculation models were created with a width of $3 \mathrm{~m}, 5 \mathrm{~m}$ and $10 \mathrm{~m}$ (Fig. 4).

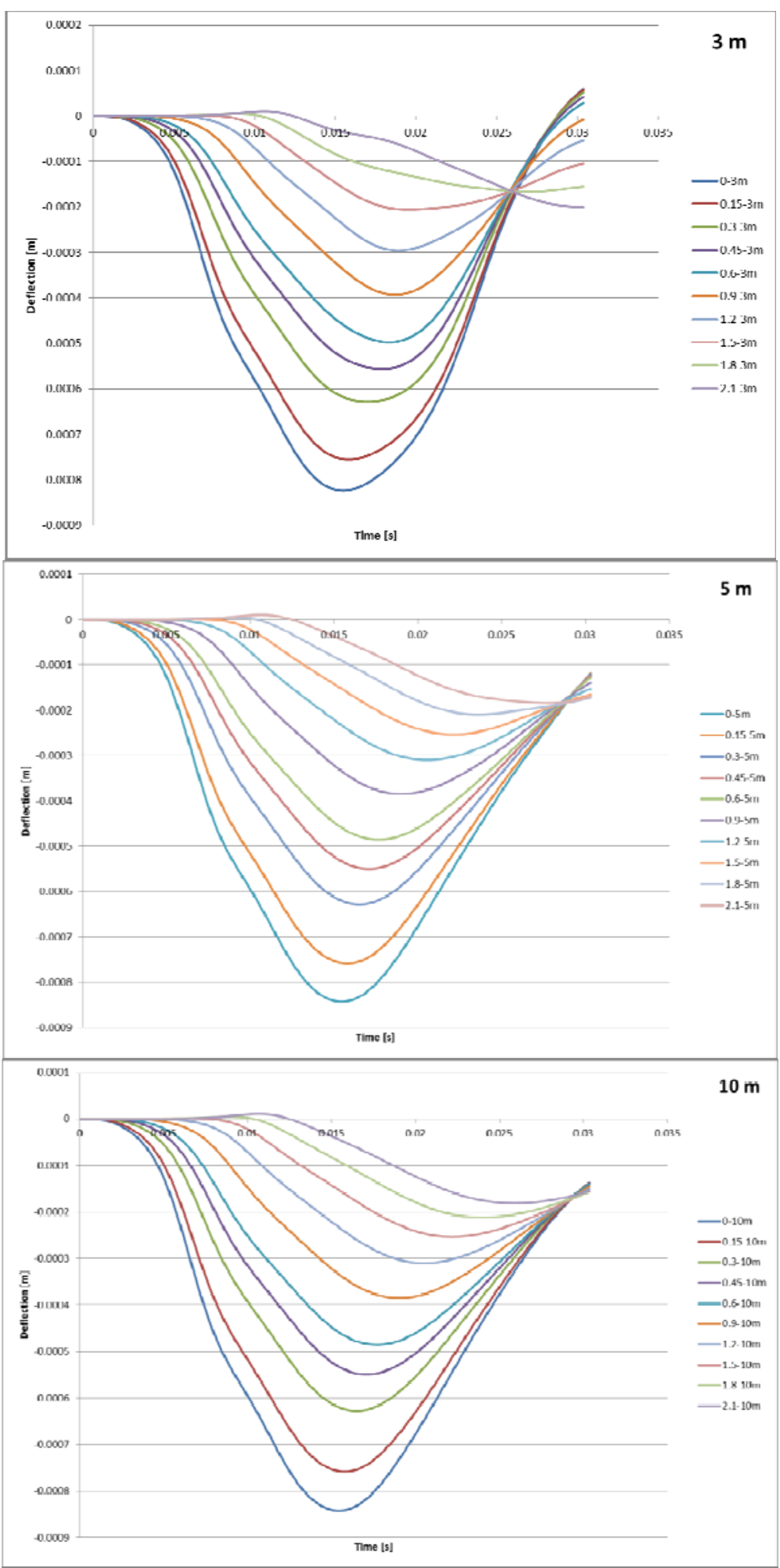

Figure 4. Time curve of pavement surface deflections in analysed points for dynamic analysis 
The comparison shows that in case of width 3 meters and 5 meters time curves are different and mainly in the points further from the axis of the load. In comparison to the model of width 5 meters and 10 meters, it is not such a visible and significant change. The same results are obtained by comparing amplitudes. It is visible that in case of deviations of time curves at further points, the time span is not long enough to display the part of curve where deflection expires. Therefore, it is difficult to estimate the amplitudes, particularly for models with smaller width. In these models amplitudes are also affected by reflection of propagated wave from the edge of the calculation model.

\section{Comparison of Results of Numerical Simulation of Pavement Response to Load Impulse}

The 2D calculation model was used for three types of pavements A1, A2, A3 in the dynamic analysis. Zero-displacements at edges of calculation model were considered. The modulus of elasticity of pavement construction layers were modified depending on temperature for each type of pavement. Thus nine numerical models of pavement have been created. Their material characteristics and thickness of structural layers are shown in Table 1.

The figure (Fig. 5) shows amplitude values for individual models of pavement labelled A1, A2 and A3 (Tab. 1). Temperatures for which modules have been determined are defined for each model. Maximum deflections of pavement are developed in load axis and gradually diminish with increasing distance from the axis of the load. The graph shows that the maximum deflections measured in the axis of the load are in the range from $0.37 \mathrm{~mm}$ to $0.42 \mathrm{~mm}$. The largest values have been obtained for the model A1 characterizing semi-rigid pavement at $0^{\circ} \mathrm{C}$. The smallest values have been obtained for the A3 model characterizing flexible pavements at $0^{\circ} \mathrm{C}$.

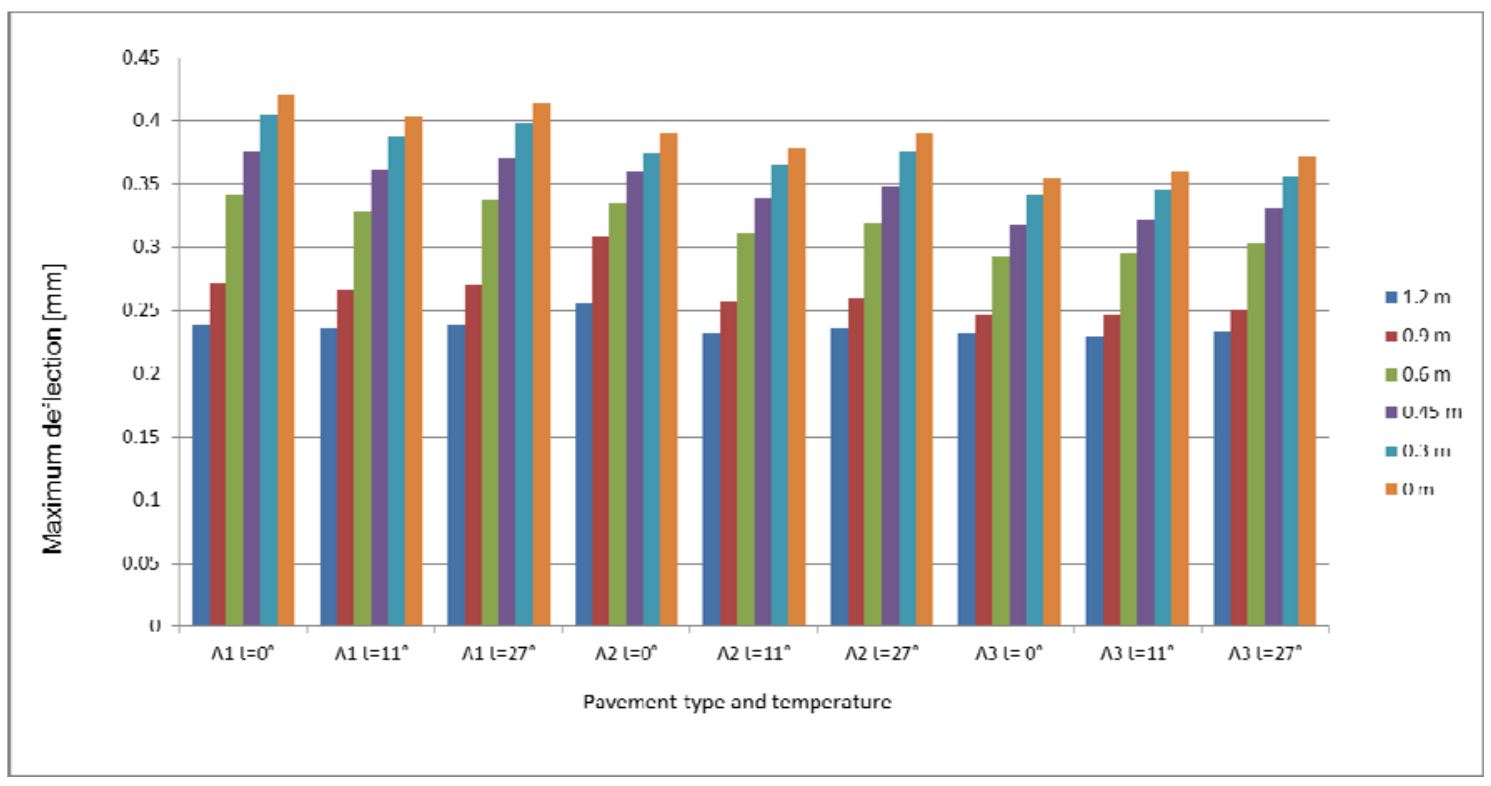

Figure 5. Changes of maximum z-displacements in dependence on the type of pavement and material characteristics of layers

The comparison shows that for models A1 and A2 characterizing the semi-rigid pavement the maximum deflection is at the load axis at $0^{\circ} \mathrm{C}$ and $27^{\circ} \mathrm{C}$ almost the same and changes significantly at $11^{\circ} \mathrm{C}$. In the case of flexible pavement, maximum deflection increases with increasing temperature and thus with the influence of the reduction in the elastic modulus of asphalt pavement layers.

The following analysis of the results has been focused on the influence of the pavement construction type on the calculated maximum deflections in the observed points. The selected reference temperature is $11^{\circ} \mathrm{C}$. For better comparison, the results of deflections in the observed points are shown as ratio to the maximum deflection in the load axis (Fig. 6). The comparison shows that the changes occur in observed points in the distance of more than $1.2 \mathrm{~m}$. At this distance it is possible to monitor the influence of thickness changes of road base. This road base has the greatest stiffness and therefore change of its thickness affects the size of deflection. The relative value of maximum deflection at a distance of $1.2 \mathrm{~m}$ decreases with increasing thickness of asphalt layers of pavement in comparison to the maximum deflection of the load axis. 


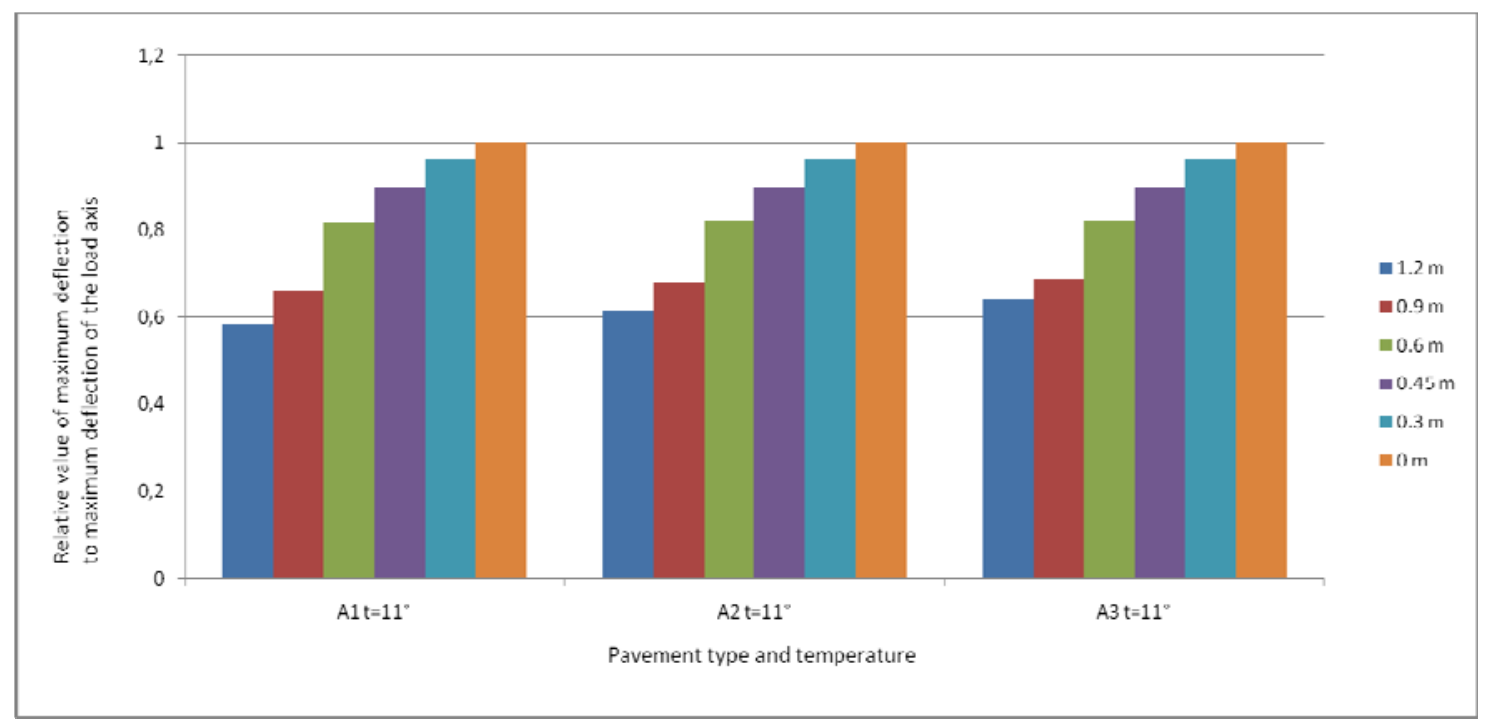

Figure 6. Comparison of deflections in observed points to the maximum deflection in load axis

To the same conclusion results also the comparison of the influence of temperature changes and thus of the change of the stiffness of pavement construction layers (Fig. 7). For comparison, the semirigid pavement model A2 has been selected. It is visible that the difference of deflection ratio in observed point versus deflection in the axis of load is significant with distance of $0.9 \mathrm{~m}$ and more. Deflection is the smallest at $0^{\circ} \mathrm{C}$, where the road base has the largest elastic modulus, and gradually decreases with reducing stiffness. It is interesting that in the distance of $1.2 \mathrm{~m}$ the difference is not so significant.

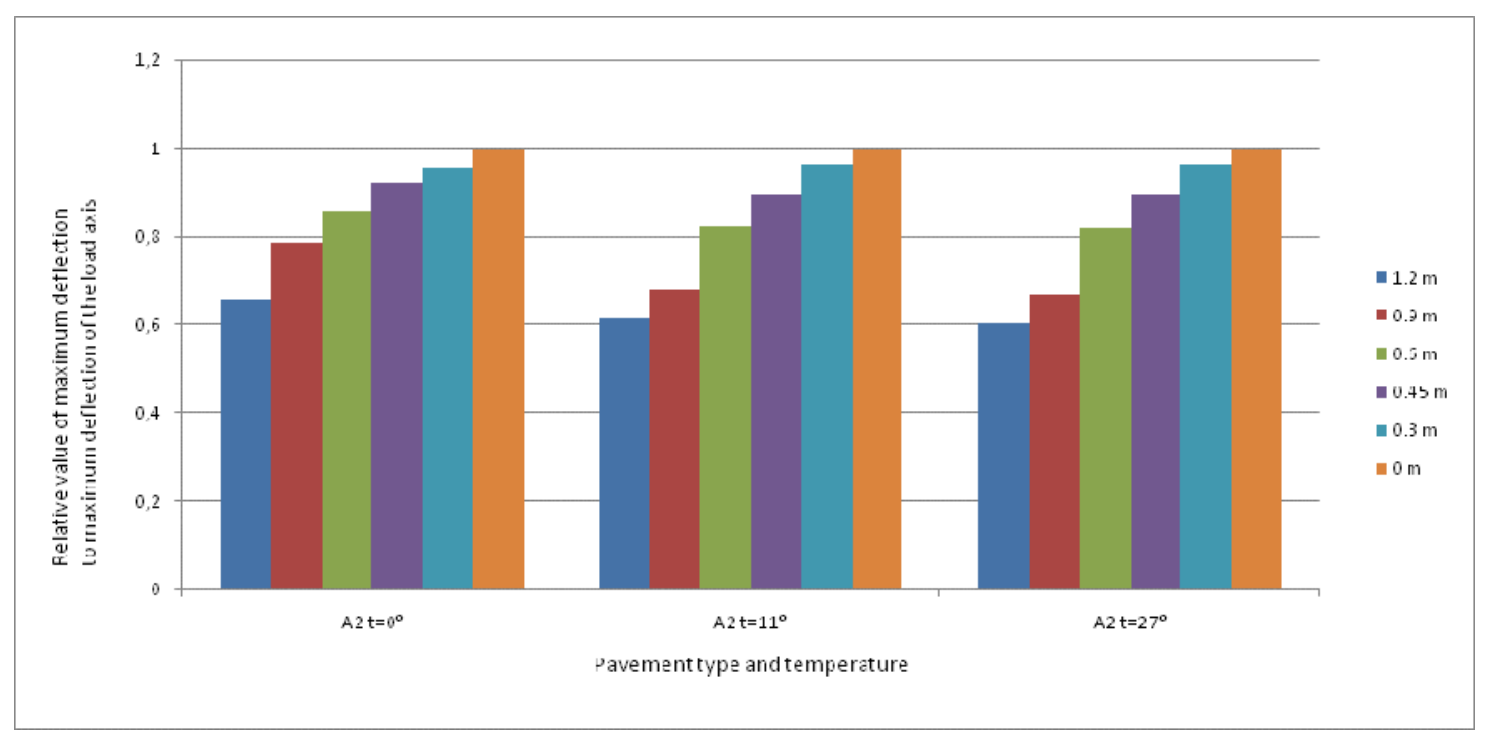

Figure 7. Influence of stiffness of road base on relative value of maximum deflection to maximum deflection in load axis

\section{Conclusions}

The signal can be evaluated by use of 2D or 3D calculation model of pavement construction. From comparison of results acquired from dynamic analysis is obvious that it is not necessary to create complicated and time-consuming 3D calculation model. The axially symmetric 2D calculation model was created for this purpose in modelling program ADINA 8.9. Dynamic analysis solved the influence of change of model width on deflections. Mathematical simulation showed that the time span for models with higher width was not sufficiently long to see the part of curve, where deflection expired. In this case, it is difficult to create an adequate calculation model and estimate the size of the modelled area so that the results are not affected by reflected propagation wave from the edge of the modelled area. 
This article deals with comparison of results of numerical simulation of pavement response to load impulse. The results of numerical simulation of 2D model shows that change of the pavement type leads to change of maximum deflection in the axis of load. Using the calculated values of maximum deflection at all points and by their comparison it is possible to determine the influence of temperature and thus also of stiffness of asphalt pavement layers on relative value of maximum deflection to maximum deflection in load axis.

\section{Acknowledgment}

This paper is a result of the research carried out during implementation of the project VEGA 1/0804/12 Influence of material composition of asphalt on characteristics of pavement surface texture, noise emission and air pollution and the project VEGA 1/0259/12 Dynamic analysis of transport structures.

\section{References}

1. Yuanqiang Gai, Zhigang Cao, Honglei Sun, Changjie Xu. (2009). Dynamic response of pavements on poroelastic half-space soil medium to a moving traffic load. Computers and Geotechnics, 36, 52-60.

2. Levenberg, Eyal. (2013). Analysis of pavement response tu subsurface deformations. Computers and Geotechnics, 50, 79-88.

3. Picoux, B., El Ayadi, A., Petit, C. (2009). Dynamic response of a flexible pavement submitted by impulse loading. Soil Dynamics and Earthquake Engineering, 29, 845-854.

4. ADINA Theory and Modelling Guide.

5. Fang, Hongbing, Haddock, John E., White, Thomas D., Hand, Adam J. (2004). On the characterization of flexible pavement rutting using creep model-based finite element analysis. Finite Elements in Analysis and Design, 41, 49-73.

6. Novak, Marc, Birgisson, Bjorn, Roque, Reynaldo. (2003). Near-surface stress states in flexible pavements using measured radial tire contact stresses and ADINA. Computers and Structures, 81, 859-870.

7. TP 3/2009. Design of flexible and semi-rigid pavements. Ministry of Transport, Posts and Telecommunications, Department of Road Transport and Roads. (In Slovak)

8. Decký, M. a.o. (2010). Designing and budgeting asphalt pavement. Žilina: University of Zhilina. (In Slovak) 